\title{
Burkitt Lymphoma Post-Transplant Lymphoproliferative Disorder
}

National Cancer Institute

\section{Source}

National Cancer Institute. Burkitt Lymphoma Post-Transplant Lymphoproliferative

Disorder. NCI Thesaurus. Code C7244.

A Burkitt lymphoma that arises in a patient with a history of organ transplantation. 